\title{
Why do men go to the doctor? Socio- demographic and lifestyle factors associated with healthcare utilisation among a cohort of Australian men
}

\author{
Marisa Schlichthorst ${ }^{1 *}$, Lena A. Sanci ${ }^{2}$, Jane Pirkis ${ }^{1}$, Matthew J. Spittal ${ }^{1}$ and Jane S. Hocking ${ }^{1}$
}

\begin{abstract}
Background: Men use health services less often than women and frequently delay seeking help even if experiencing serious health problems. This may put men at higher risk for developing serious health problems which, in part, may explain men's higher rates of some serious illnesses and shorter life span relative to women. This paper identifies factors that contribute to health care utilisation in a cohort of Australian men by exploring associations between socio-economic, health and lifestyle factors and the use of general practitioner (GP) services.
\end{abstract}

Methods: We used data from Ten to Men, the Australian Longitudinal Study on Male Health. Health care utilisation was defined in two ways: at least one GP visit in the past 12 months and having at least yearly health check-ups with a doctor. Associations between these two measures and a range of contextual socio demographic factors (education, location, marital status, country of birth, employment, financial problems etc.) as well as individual health and lifestyle factors (self-rated health, smoking, drinking, healthy weight, pain medication) were examined using logistic regression analysis. The sample included 13,763 adult men aged 18 to 55 years. Analysis was stratified by age (18 to 34 year versus 35 to 55 years).

Results: Overall, $81 \%$ (95\% Cl: 80.3-81.6) of men saw a GP for consultation in the 12 months prior to the study. The odds of visiting a GP increased with increasing age $(p<0.01)$, but decreased with increasing remoteness of residence $(p<0.01)$. Older men, smokers and those who rate their health as excellent were less likely to visit a GP in the last 12 months, but those on daily pain medication or with co-morbidities were more likely to have visited a GP. However, these factors were not associated with consulting a GP in the last 12 months among young men. Overall, $39 \%$ (95 \% Cl: 38.3-39.9) reported having an annual health check. The odds of having an annual health check increased with increasing age $(p<0.01)$, but showed no association with area of residence $(p=0.60)$. Across both age groups, the odds of a regular health check increased with obesity and daily pain medication, but decreased with harmful levels of alcohol consumption.

Conclusion: The majority of men (61\%) did not engage in regular health check-up visits, representing a missed opportunity for preventative health care discussions. Lower consultation rates may translate into lost opportunities to detect and intervene with problems early and this is where men may be missing out compared to women.

\footnotetext{
* Correspondence: marisa.schlichthorst@unimelb.edu.au

${ }^{1}$ Melbourne School of Population and Global Health, the University of

Melbourne, Melbourne 3010, Australia

Full list of author information is available at the end of the article
} 


\section{Background}

Numerous studies have found that men overall have lower rates of medical help seeking and health care utilisation compared with women [1-6]. This behaviour has been observed across a diverse range of health problems such as general physical health problems, mental health problems, life-stresses, and alcohol and substance use [7-14]. Data on primary care in the UK show that among those aged 21 to 58 years, men consult a general practitioner (GP) half as often as women [15], a difference that wasn't explained by women attending for reproductive health reasons. There are also considerable gender differences in terms of health outcomes - life expectancy is greater in women compared with men in most developed countries and men also suffer higher rates of many non-communicable diseases including heart disease, lung cancer, chronic respiratory disease, alcoholism and suicide [2]. It is possible that men's lower rates of health care utilisation may be contributing to these differences in health outcomes [16].

Primary care provides a crucial role in preventive health care activities including promoting smoking cessation, responsible alcohol consumption, weight control and physical activity and undertaking screening activities including blood pressure monitoring, cholesterol and blood glucose measurement and cancer screening [17]. Any difference in consultation patterns between the sexes could therefore have important implications for future health outcomes particularly given that preventive activities are often conducted opportunistically when the patient presents for other reasons in general practice. Infrequent attendees have been shown to receive less preventive care [18]. Higher consultation rates may therefore translate into greater opportunities to detect and intervene with problems early and this is where men may be missing out compared to women [19]. Once detected however, men and women with common morbidities such as depression and cardiovascular disease show similar patterns of health care utilisation [15].

Patterns of health care utilisation are complex and it is likely that a variety of masculinity ideologies, norms, and gender roles play a part in discouraging men's help seeking [20]. Most studies investigating health care utilisation compare genders and hence have limited scope to examine factors associated with health care utilisation among men and to explore differences across subgroups of men [20, 21]. Besides gender, socio-economic status, access to services, cost of services, age, level of education and marital status have been associated with service utilisation [22-26]. Negative attitudes to help seeking have been discussed as a barrier to help seeking in men $[20,27,28]$, particularly in the context of mental health problems $[26,29,30]$. Gender specific attitudinal and behavioural factors are also important predictors for medical services utilisation [1]. Over the last decade a growing body of research links men's reluctance to seek help to adherence to traditional masculine norms (e.g. stoicism) [22, 31-44]. However, these studies lack evidence on the processes driving this association.

Research into male-specific patterns of health care utilisation has been limited by small sample size and/or focus on specific or high prevalence male health issues. To date a comprehensive analysis of social, behavioural and socio-economic factors associated with health care utilisation in men and how this may change over time as men age is missing from the literature. We have the unique opportunity to explore health care utilisation among men in an ongoing cohort study of Australian men aged 18 to 55 years. In this paper, we present the cross-sectional analysis investigating associations with two measures of health care utilisation (past visit to a general practitioner (GP) and regular health check-ups for men) and a number of contextual socio-demographic characteristics and general health and lifestyle choices at recruitment. These data will form the baseline for future analyses in subsequent waves of the data collection of the cohort.

\section{Methods}

\section{Participants}

We used data from Ten to Men (the Australian Longitudinal Study on Male Health) a population-based cohort study capturing a range of health outcomes, health behaviours and related risk factors (including social determinants). The study methodology has been fully described by Currier and colleagues in this supplement of BMC Public Health [45]. Briefly, participants were recruited from households between October 2013 and July 2014 based on a stratified, multi-stage, random cluster sampling design. Regional areas were over-sampled to increase the numbers in these groups and allow for meaningful analysis in these population sub-groups. Men were asked to complete a detailed questionnaire that covered a range of health outcomes, behaviours and related risk factors. The final sample consists of 15,988 male participants aged between 10 and 55 years. For the purpose of this paper, respondents under 18 years of age were excluded from the analysis leaving the total number of participants at 13,763 men. About $60 \%$ of men live in major cities, $23 \%$ in inner regional and $19 \%$ in outer regional areas. Compared with Australian census data, older and middle aged men were slightly over represented with about a third of men each in the 35 to 44 years and the 45 to 55 years age groups, while 18 to 24 year old men were underrepresented at about $15 \%$ of the sample. The majority was born in Australia (77 \%), completed year 12 of secondary school (60\%), were married or in a de-facto relationship (67\%), were employed (86 \%), and a father to at least one child (66\%). 


\section{Measures}

Two questions from the Ten to Men adult questionnaire were used to assess health care utilisation. The first asked participants to name the health services or type of health professional (e.g., dentist, GP, chiropractor etc.) with whom they had consulted in the 12 months prior to the survey. A list of 25 services was provided including an option to name others. Participants marked "yes" to all services that applied to them. The second question asked participants to state how often they saw their family doctor for a general health check-up, i.e. not because they are sick or injured. The response options were more than once a year, once a year, less frequently, and never.

The predictors of health care utilisation we examined included a range of socio-demographic characteristics and health and lifestyle factors. Region of residence follows the Australian Statistical Geographical Standard Classification and was coded into major city, inner regional and outer regional areas [46]. Participants' age was recoded into four groups: 18 to 24 years, 25 to 34 years, 35 to 44 years and 45 to 55 years. Highest level of secondary school education was aggregated for those who completed year 12 of secondary school versus those who had not completed secondary school. Participants born outside Australia were combined and contrasted against those born in Australia. Due to low numbers of respondents in some categories 'marital status' was recoded into three categories: never married, widowed/ divorced/separated, and married/de facto. Employment status captured employed versus currently unemployed men. Based on the number of children per participant a new variable was created for being a father (i.e. having at least one child) and not being a father (i.e. having no children). Financial difficulty was assessed using six questions from a national expenditure survey: i.e. not filling or collecting a prescription medicine; not getting a medical test, treatment or follow-up that was recommended by a doctor; limiting fruit or vegetable consumption; not paying for electricity, gas or telephone bills on time; and having to ask friends or family for financial help [47]. We aggregated responses across these items and recoded into a dichotomous variable to identify participants who experienced at least one financial difficulty in the past 12 months. Whether or not the participant had private health insurance was also included as a binary variable.

The health and lifestyle factors we examined were participants' current smoking status (smoker versus nonsmoker), harmful or hazardous alcohol consumption (derived from the Alcohol Use Disorder Identification Test - AUDIT) [48], and obesity (derived from the body mass index (BMI) and categorised as obese with BMI greater or equal 30 and non-obese with BMI less than 30). A new variable was generated to capture participants who used over the counter pain-medication on a daily basis. Finally, self-rated general health was measured using the first question of the SF12 Health Survey [49]. The original 5-point scale was dichotomized into very good-excellent health versus poor-fair-good health. To control for the presence of health conditions, a comorbidity score was derived as an aggregate across 19 high prevalence conditions indicating if the participant was diagnosed with these in the past 12 months. Participants were then grouped into four categories: diagnosed with no health condition in the previous 12 months, diagnosed with one health condition, diagnosed with two health conditions and diagnosed with 3 or more health conditions.

\section{Statistical analysis}

Our primary outcome was consultation with a GP in the last 12 months defined as whether or not the participant had visited a GP for their own health at least once during the last 12 months. Our secondary outcome was whether or not the participant had a regular check-up at least once per year (defined as visiting a GP for a general health check-up, not because he was sick or injured).

Proportions and $95 \%$ confidence intervals (CI) were first calculated to estimate health care use. Trends by age and level of geographic remoteness were assessed using the Score test. We used logistic regression to assess associations between socio-demographic and health and lifestyle factors and the primary and secondary outcomes. In a first step we ran regression analysis accounting for interaction effects between age and other exposures to identify any important interaction. Where the interaction effects were significant we stratified the analysis by age groups. To investigate any bias associated with missing data, the demographic characteristics of those included in the analysis were compared with those excluded. All analysis use unweighted data and were performed using Stata/IC 13.1.

\section{Results}

Consultation with a GP in the last 12 months

Of the 13,763 participating men, 11,148 (81 \%, $95 \% \mathrm{CI}$ : 80.3-81.6) had consulted with their GP in the 12 months prior to the study. Participants also reported consulting with a dentist (39\%), specialist doctors (25\%), pharmacist (20\%), optometrist (13\%), chiropractor (14\%), physiotherapists $(13 \%)$, and nurses $(6.5 \%)$ in the preceding 12 months. Overall, 12,264 men (89 \%, 95 \% CI: 88.6-89.6) reported consulting with at least one healthcare provider in the last 12 months with participants visiting an average of 2.5 different health services $(\mathrm{SD}=2.13$, 95 \% CI: 2.44-2.51). There was a trend towards increasing odds for visiting a GP in the last 12 months as age increased $(p<0.01)$ and as remoteness levels decreased $(p<0.01)$. A small proportion of men $(8 \%, 95 \%$ CI: 
7.3-8.2) indicated that they were unable to access health care when needed in the last 12 months. For this group, there was no evidence of a trend of increasing or decreasing odds by age $(p=0.35)$, but there was evidence for a trend of increasing odds by remoteness level $(p<0.01)$.

Preliminary regression analysis for GP visits found significant interaction effects between age and health check-up $(p=0.006)$, employment status $(p=0.002)$ and positively self-rated health $(p=0.004)$. For the ease of reporting we stratified the final regression models by age groups.

Multivariate analysis showed that among 18 to 34 years old participants, the odds of consultation with a GP in the last 12 months were increased among those who had regular yearly health check-ups $(\mathrm{OR}=4.5,95 \%$ CI: 3.4-5.9), for those who had been diagnosed with health conditions and was greatest for those with three or more conditions compared with none $(\mathrm{OR}=4.4$, $95 \%$ CI: 2.2-8.6), for those who completed secondary school $(\mathrm{OR}=1.3,95 \% \mathrm{CI}: 1.0-1.6)$, were born in Australia $(\mathrm{OR}=1.3,95 \% \mathrm{CI}: 1.0-1.7)$, were in employment $(\mathrm{OR}=1.5,95 \% \mathrm{CI}: 1.2-1.9)$, had private health insurance $(\mathrm{OR}=1.3,95 \% \mathrm{CI}$ : 1.1-1.6), had experienced financial difficulties in the past 12 months (OR $=1.3,95 \%$ CI: 1.0-1.3), and those who are a father $(\mathrm{OR}=1.4,95 \% \mathrm{CI}: 1.1-1.8)$. The odds of consultation with a GP decreased in this age group with residing outside of a major city (inner regional area OR $=0.7,95 \% \mathrm{CI}$ : $0.5-0.9$; outer regional area $\mathrm{OR}=0.7,95 \%$ CI: 0.5-0.9). None of the health and lifestyle factors showed significant associations (Table 1).

Among 35 to 55 years old participants, the odds of consultation with a GP were increased with: having regular yearly health check-ups (OR $=7.0,95 \% \mathrm{CI}$ : 5.59.0); with an increasing number of heath conditions and was greatest for those with three or more conditions compared with none (OR =3.2, $95 \% \mathrm{CI}$ : $2.0-4.9)$; with being married $(\mathrm{OR}=1.6,95 \% \mathrm{CI}$ : $1.2-2.2)$; having private health insurance $(\mathrm{OR}=1.2,95 \% \mathrm{CI}$ : $1.0-1.5)$; and taking daily pain medication ( $\mathrm{OR}=1.9,95 \% \mathrm{CI}: 1.2-2.9)$. The odds of consultation with a GP were decreased in this age group with residing in inner regional Australia (OR = 0.8, 95 \% CI: 0.6-0.9), but no association was observed for those residing in outer regional Australia. Further, the odds for visiting a GP were reduced for smokers $(\mathrm{OR}=0.7,95 \% \mathrm{CI}: 0.5-0.8)$ and rating one's own health as excellent or very good compared with good or less than $\operatorname{good}(\mathrm{OR}=0.7,95 \%$ CI: 0.6-0.8) (Table 1$)$.

\section{Regular health check-up visits at least once per year}

A total of 5167 men (39\%, $95 \%$ CI: 38.3-39.9) reported visiting a family doctor for a general health check at least once per year. There was evidence for a trend towards increasing odds for having at least yearly health check-ups with increasing age $(p<0.001)$ but no significant trend with remoteness of residence was found $(p=0.596)$.

Significant interaction effects were found between age and GP visit in the past 12 months $(p=0.003)$, age and marital status $(p=0.041)$, and age and the number of diagnosed health conditions in the past 12 months $(p<0.001)$. In Table 1 we report the stratified final regression models for regular health check-up visits by age groups.

Among 18 to 34 years old participants, multivariate analysis found that the odds of having regular yearly health check-ups at least once a year were increased with: having visited the GP in the past 12 months (OR = 4.4, $95 \%$ CI: 3.3-5.9); having been diagnosed with two or more health conditions in the past 12 months $(\mathrm{OR}=$ 1.8, $95 \%$ CI: $1.3-2.3)$; and being obese (OR $=1.4,95 \%$ CI: $1.2-1.7)$. In this age group, the odds of having yearly health check-ups were decreased for men born in Australia $(\mathrm{OR}=0.8,95 \% \mathrm{CI}$ : 0.6-1.0), being married or in a de-facto relationship ( $\mathrm{OR}=0.7,95 \% \mathrm{CI}$ : 0.5-0.8), having experienced financial difficulties in the past 12 months $(\mathrm{OR}=0.8,95 \% \mathrm{CI}: 0.7-1.0)$, and engaging in harmful drinking $(\mathrm{OR}=0.8,95 \% \mathrm{CI}: 0.7-0.9)$.

Among 35 to 55 years old participants, the odds for regular check-ups were increased with: having visited the GP in the past 12 months (OR = 7.0, $95 \%$ CI: 5.5-9.0); experiencing an increasing number of heath conditions and was greatest for those with three or more conditions compared with none $(\mathrm{OR}=3.1,95 \% \mathrm{CI}$ : $2.5-3.8)$; being widowed, divorced or separated $(\mathrm{OR}=1.4,95 \% \mathrm{CI}$ : $1.0-1.8)$; having private health insurance $(\mathrm{OR}=1.3,95 \%$ CI: 1.1-1.4); being obese (OR = 1.3, $95 \% \mathrm{CI}: 1.2-1.5)$; and taking daily pain medication ( $\mathrm{OR}=1.6,95 \% \mathrm{CI}$ : $1.3-1.9)$. A decrease in odds for having regular check-ups was found for those who completed secondary school $(\mathrm{OR}=0.7,95 \% \mathrm{CI}: 0.7-0.8)$, experienced financial difficulties $(\mathrm{OR}=0.7,95 \% \mathrm{CI}: 0.6-0.8)$, and for those who engaged in harmful drinking (OR = 0.7, $95 \%$ CI: 0.7-0.8).

Overall, 4262 (31\%) men were excluded from the multivariate analysis because of missing data. Those excluded from the analysis were more likely to be younger $(p<0.01)$, less likely to be married $(p<0.01)$, less likely to have completed secondary school education $(p<0.01)$ and more likely to have been born overseas $(p<0.01)$. There was no difference in remoteness of residence $(p=0.32)$.

\section{Discussion}

The findings of our study are consistent with the Australian data on male consultations with the GP - BEACH data shows $80 \%$ of males in the population saw a GP at least once in 2013 to 2014. While this suggests that a high proportion of males are seeing a GP on a regular or yearly bases it must be stressed that these proportions fall short 


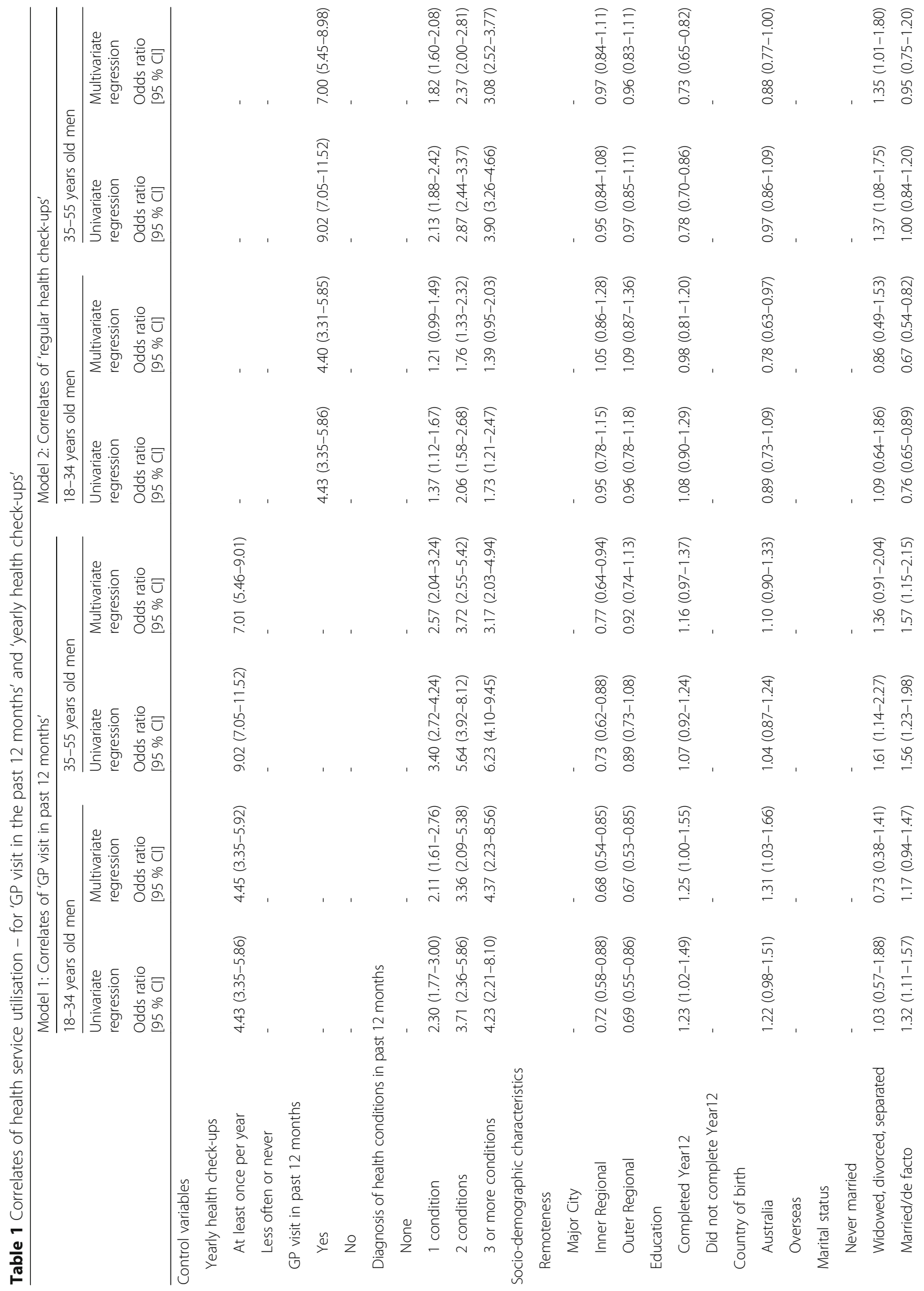




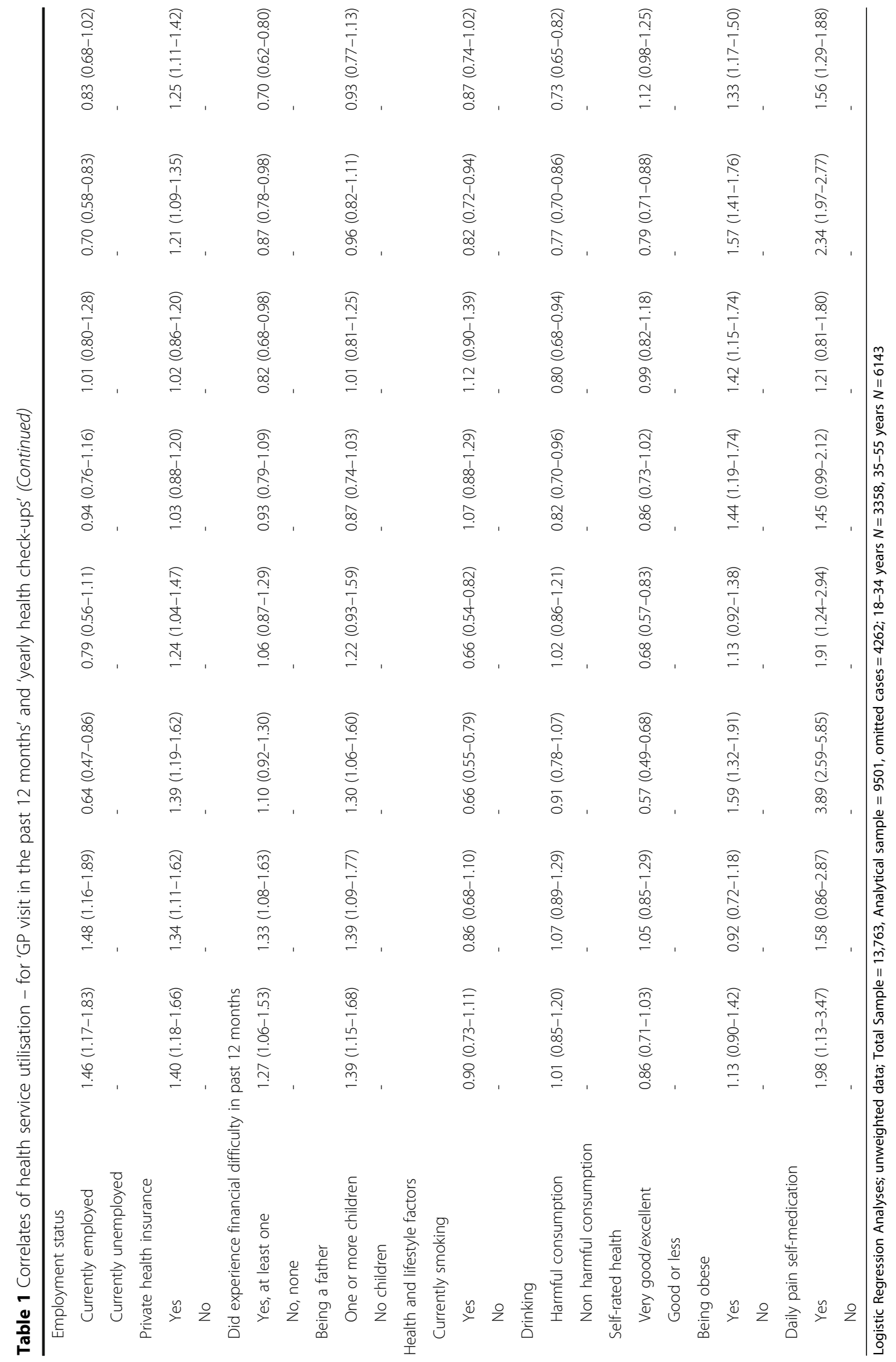


compared to women's rates of GP visits [6]. This paper highlights some of the complexities that research into men's health care utilisation and help seeking faces.

We found that $81 \%$ of participants reported having consulted a GP in the last 12 months with increasing odds of visiting a GP as age increases and decreasing odds as remoteness of residence increases. We also found that only $39 \%$ of men had regular health checkups and while the odds increased with age, there was no association with the remoteness of residence. Our analyses show that a person's general health status affects the odds of visiting a GP. Men with very good to excellent self-rated health were less likely to have visited a GP in the last 12 months but those taking pain medication on a daily basis and those who were diagnosed with one or more health conditions were more likely. The magnitude of effects was greater for older than younger men. Across men of all ages, having private health insurance increased the odds for a GP visit in the past 12 months.

Socio-demographic factors showed fewer significant effects on the odds for visiting a GP in older men compared with younger men. We found that those living outside of a major city were less likely to attend a GP in the last 12 months. This raises issues of equity in terms of healthcare access for those living in rural and regional Australia. People living in rural areas have less choice of healthcare services available and they are more likely to have longer travel distances to attend these services mostly without access to public transport [50-52]. Medical workforce shortages in rural areas makes access to health services even more challenging [53]. Rural health services have to provide care to a more dispersed population than urban services while at the same time, are often smaller, less resourced and face additional expenses associated with distance [54].

Health and lifestyle factors showed greater relevance among older men with those smoking and those with excellent to good self-rated health attending the GP less often. Of concern was that smokers were less likely to have consulted a GP in the last 12 months which means that the opportunity to influence lifestyle choices or even monitor health risks in this population group is diminished. It has been well established that smoking is associated with lower socio-economic status $[55,56]$, but it is a concern that even after adjusting for socio-economic variables such as education, remoteness and financial difficulties, our study shows that older smokers are less engaged with the healthcare system. The factors that were most strongly related to past GP visits seem to measure ill health (e.g., taking daily pain-medication, having been diagnosed with health conditions over the past 12 months and rating own health less positive). This suggests that men may see a GP as particular health conditions present or on a needs basis, rather than planning their visit in advance.
In contrast to GP visits, the odds of engaging in regular health check-ups were reduced by having finished secondary school, being born in Australia, having experienced financial difficulties or being married. In addition to factors measuring ill health (i.e. taking daily pain medication and number of diagnosed health conditions) the health risk factor of being obese increased the odds for regular health check-ups. While this provides an opportunity for GPs to discuss healthy lifestyle choices with at risk men, the overall low number of men choosing to see a doctor for a general health check-up is reducing the significance of this opportunity. Further, engaging in harmful alcohol consumption decreased the odds for regular health check-ups meaning a reduced opportunity for intervention by a doctor or medical professional.

The majority of men $(61 \%)$ did not engage in regular health check-up visits, which we believe represents a missed opportunity for preventative health care discussions. Health check-ups have been demonstrated to improve the frequency of preventive care and support regular discussions on changing health behaviour in middle age $[57,58]$ and have also been found to improve the quality of preventative care [59]. Further, adults who received ongoing care from regular visits to the GP are found to be more likely to receive the preventive services as recommended by policy guidelines [18]. Lower consultation rates may therefore translate into lost opportunities to detect and intervene with problems early and this is where men may be missing out compared to women [19].

It is possible that existing funding mechanisms in Australian general practice are deterrents against routine health checks [60]. For example, among those aged 45 to 49 years with documented risk factors for chronic disease, GPs can only claim one cardiovascular health check consultation over this five year period $[17,61]$. Providing GPs with more options to initiate preventive health care discussions with patients could increase health care utilisation among men, especially for problems where stigma is perceived or experienced (i.e. mental health problems) [14]. Regular contact with a medical professional can help normalize medical consultations for men allowing them to build trust with medical professionals and be more inclined to be proactive in their health management or seek help when issues arise. Failing to seek help for symptoms can lead to delayed diagnosis and treatment and increase the long term burden on the healthcare system [62]. However, it should be acknowledged, that the benefits of increased health care utilisation for preventive health checks do need to be balanced against the potentially increased costs of screening tests and other medical investigations. Future analyses of the Ten to Men cohort study will involve linkage with government health care utilisation records (Medicare) providing further opportunities to explore 
associations between health care utilisation and health outcomes.

There are several limitations of this analysis which must be considered when interpreting the data. Firstly, we did not include social or emotional and cognitive psychological factors as predictors (e.g., masculine norms, gender roles, or attitudes to help seeking). In the context of health services utilisation it is plausible that attitudes to health and help seeking play an important role [27, 28]. Visiting the doctor for regular health check-ups might see a different sub-group of men and most likely those men who show initiative in looking after their health and are engaged with their health and health services in general. In contrast, GP visits in the last 12 months as an outcome measure might capture those men who saw a doctor because of a specific health care need (i.e. illness or injury). However, investigating the role of attitudes and social roles requires more complex analysis which was beyond the scope of this paper. Secondly, the measurement of health care utilisation used in this paper is based on self-report which is likely to be subject to recall bias. At the time of analysis we did not have access to participants' health records including types of services accessed, diagnostic tests performed and medications prescribed. These data would add crucial information to further our understanding of this field and address any bias caused by self-report.

The strengths of this analysis are that a range of sociodemographic and health-related variables were available allowing for a comprehensive analysis of potential associates of health care utilisation in men. Any contact with a GP offers the opportunity for diagnosis and intervention. However, more research is needed to better understand differences in sub-groups of men in terms of what motivates their help seeking behaviour. For example, a profile analysis of those men who do not use any health services could provide useful information to guide interventions or health promotion strategies to reach them for healthcare.

\section{Conclusion}

Males' healthcare utilisation is varied and is greatly influenced by age and the interaction between age and general health status. The proportion of men having regular health check-ups is generally much lower than the proportion of men visiting a GP in the past. Further, older men engage more often in regular health check-ups which might be driven by a need to monitor existing health conditions. The differences between the two measures of health care utilisation indicate that past GP visits and regular check-up visits are driven by different contextual and individual behavioural factors. Our findings suggest that men may see a GP only as needed (e.g., for acute illness or injury) and may not plan their visit on a regular basis, and that contextual factors are of higher relevance in deciding on whether or not to see a GP. More research is needed to better understand what social, behavioural and health factors influence different aspects of medical help seeking in men. However, lower check-up rates may translate into lost opportunities to detect and intervene with problems early and this is where men may be missing on receiving the preventative health care when needed.

\section{Acknowledgements \\ The research on which this paper is based on was conducted as part of the Australian Longitudinal Study on Male Health by the University of \\ Melbourne. We are grateful to the Australian Government Department of \\ Health for funding and to the boys and men who provided survey data. \\ Declaration \\ Publication of this article was funded by the Ten to Men Study. This article has been published as part of BMC Public Health Vol 16 Suppl 3, 2016: Expanding the knowledge on male health: findings from the Australian Longitudinal Study on Male Health (Ten to Men). The full contents of the supplement are available online at https://bmcpublichealth.biomedcentral. com/articles/supplements/volume-16-supplement-3.}

\section{Availability of data and materials}

Ten to Men response data are available to researchers via a request and review process. Information on accessing Ten to Men data is available at http://www.tentomen.org.au/index.php/researchers.html. Copies of Wave 1 questionnaires, Wave 1 data books, and the Ten to Men Data User's Manual are also available at that site.

Enquires about potential collaborations including sub-studies involving members of the Ten to Men cohort can be addressed to the Study Coordinator at info@tentomen.org.au.

\section{Authors' contributions}

MS, LS, M Spittal and JH were responsible for the analytical design. MS and M Spittal undertook data analysis. MS, M Spittal, and JH were involved in interpreting the analysis. MS drafted the manuscript. All authors undertook critical revision of the manuscript and have approved this manuscript version for submission.

\section{Competing interests}

The authors declare that they have no competing interests.

Consent for publication

Not applicable.

\section{Ethics approval and consent to participate}

The Australian Longitudinal Study on Male Health was approved by the University of Melbourne Human Research Ethics Committee (HREC

1237897 \& 1237376). Participants provided written consent for their participation.

\section{Author details}

${ }^{1}$ Melbourne School of Population and Global Health, the University of Melbourne, Melbourne 3010, Australia. ²Department of General Practice, the University of Melbourne, Melbourne 3010, Australia.

\section{Published: 31 October 2016}

\section{References}

1. Green CA, Pope CR. Gender, psychosocial factors and the use of medical services: a longitudinal analysis. Soc Sci Med. 1999;48(10):1363-72.

2. Mansfield AK, Addis ME, Courtenay W. Measurement of men's help seeking: development and evaluation of the barriers to help seeking scale. Psychol Men Masculinity. 2005;6(2):95.

3. Australian Institute of Health and Welfare. A snapshot of men's health in regional and remote Australia. In: AlHW, editor. Rural health series no 11. Canberra: AlHW; 2010.

4. Welfare AloHa. The health of Australia's males, June ed. Canberra: AlHW; 2011. 
5. Banks I, Baker P. Men and primary care: improving access and outcomes. Trends in Urology \& Men's Health. 2013;4(5):39-41.

6. Bayram C, Valenti L, Britt H. General practice encounters with men. Aust Fam Physician. 2016;45(4):171-4.

7. Hale S, Grogan S, Willott S. Patterns of self-referral in men with symptoms of prostate disease. Br J Health Psychol. 2007;12(3):403-19.

8. Husaini BA, Moore ST, Cain VA. Psychiatric symptoms and help-seeking behavior among the elderly: an analysis of racial and gender differences. J Gerontol Soc Work. 1994;21(3-4):177-96.

9. McKay JR, Rutherford MJ, Cacciola JS, Kabasakalian-McKay R, Alterman Al. Gender differences in the relapse experiences of cocaine patients. J Nerv Ment Dis. 1996;184(10):616-22.

10. Padesky CA, Hammen CL. Sex differences in depressive symptom expression and help-seeking among college students. Sex Roles. 1981;7(3):309-20.

11. Rickwood DJ, Braithwaite VA. Social-psychological factors affecting helpseeking for emotional problems. Soc Sci Med. 1994;39(4):563-72.

12. Thom B. Sex differences in help-seeking for alcohol problems-1. The barriers to help-seeking. Br J Addict. 1986;81(6):777-88.

13. Weissman MM, Klerman GL. Sex differences and the epidemiology of depression. Arch Gen Psychiatry. 1977;34(1):98-111.

14. Yousaf $O$, Grunfeld EA, Hunter MS. A systematic review of the factors associated with delays in medical and psychological help-seeking among men. Health Psychology Review. 2013(ahead-of-print):1-13

15. Wang Y, Hunt K, Nazareth I, Freemantle N, Petersen I. Do men consult less than women? An analysis of routinely collected UK general practice data. BMJ Open. 2013;3(8):e003320.

16. Hale S, Grogan S, Willott S. Male GPs' views on men seeking medical help: a qualitative study. Br J Health Psychol. 2010;15(4):697-713.

17. RACGP. Guidelines for preventive activities in general practice. In: Vol. 2016. 8th ed. Australia: The Royal Australian College of General Practitioners; 2012.

18. Mclsaac WJ, Fuller-Thomson E, Talbot Y. Does having regular care by a family physician improve preventive care? Can Fam Physician. 2001;47(1):70-6.

19. Harris MF, McKenzie S. Men's health: what's a GP to do? Med J Aust. 2006; 185(8):440.

20. Addis ME, Mahalik JR. Men, masculinity, and the contexts of help seeking. Am Psychol. 2003;58(1):5

21. Galdas PM, Cheater F, Marshall P. Men and health help-seeking behaviour: literature review. J Adv Nurs. 2005;49(6):616-23.

22. Davies J, McCrae BP, Frank J, Dochnahl A, Pickering T, Harrison B, Zakrzewski $\mathrm{M}$, Wilson K. Identifying male college students' perceived health needs, barriers to seeking help, and recommendations to help men adopt healthier lifestyles. J Am Coll Heal. 2000;48(6):259-67.

23. Doherty DT, Kartalova-O'Doherty Y. Gender and self-reported mental health problems: predictors of help seeking from a general practitioner. $\mathrm{Br} J$ Health Psychol. 2010;15(1):213-28.

24. Holden C, Jolley D, McLachlan R, Pitts M, Cumming R, Wittert G, Handelsman D, De Kretser D. Men in Australia Telephone Survey (MATeS): predictors of men's help-seeking behaviour for reproductive health disorders. Med J Aust. 2006;185(8):418-22.

25. Koopmans GT, Lamers LM. Gender and health care utilization: the role of mental distress and help-seeking propensity. Soc Sci Med. 2007;64(6):1216-30.

26. Mackenzie C, Gekoski W, Knox V. Age, gender, and the underutilization of mental health services: the influence of help-seeking attitudes. Aging and Mental Health. 2006;10(6):574-82.

27. Ang RP, Lim KM, Tan A-G, Yau TY. Effects of gender and sex role orientation on help-seeking attitudes. Curr Psychol. 2004;23(3):203-14.

28. Morgan NT, Robinson M. Students' help-seeking behaviours by gender, racial background, and student status. Can J Couns. 2003;37(2):151-66.

29. Möller-Leimkühler AM. Barriers to help-seeking by men: a review of sociocultural and clinical literature with particular reference to depression. J Affect Disord. 2002;71(1):1-9.

30. Vogel DL, Wester SR. To seek help or not to seek help: the risks of selfdisclosure. J Couns Psychol. 2003:50(3):351

31. Coles R, Watkins F, Swami V, Jones S, Woolf S, Stanistreet D. What men really want: a qualitative investigation of men's health needs from the Halton and St Helens Primary Care Trust men's health promotion project. Br J Health Psychol. 2010;15(4):921-39.

32. Gough B. Try to be healthy, but don't forgo your masculinity: deconstructing men's health discourse in the media. Soc Sci Med. 2006;63(9):2476-88.

33. Gough B. The psychology of men's health: maximizing masculine capital. Health Psychol. 2013;32(1):1.
34. Jeffries M, Grogan S. 'Oh, I'm just, you know, a little bit weak because I'm going to the doctor's': young men's talk of self-referral to primary healthcare services. Psychol Health. 2012;27(8):898-915.

35. Johnson JL, Oliffe JL, Kelly MT, Galdas P, Ogrodniczuk JS. Men's discourses of help-seeking in the context of depression. Sociology of health \& illness. 2012;34(3):345-61.

36. Mahalik JR, Burns SM, Syzdek M. Masculinity and perceived normative health behaviors as predictors of men's health behaviors. Soc Sci Med. 2007;64(11):2201-9.

37. Noone JH, Stephens C. Men, masculine identities, and health care utilisation. Sociology of health \& illness. 2008;30(5):711-25.

38. O'Brien R, Hunt K, Hart G. 'It's caveman stuff, but that is to a certain extent how guys still operate': men's accounts of masculinity and help seeking. Soc Sci Med. 2005;61(3):503-16.

39. O'Loughlin RE, et al. Role of the gender-linked norm of toughness in the decision to engage in treatment for depression. Psychiatric Services. 2011;62(7):740-6.

40. Pederson EL, Vogel DL. Male gender role conflict and willingness to seek counseling: testing a mediation model on college-aged men. J Couns Psychol. 2007;54(4):373.

41. Rochlen AB, Paterniti DA, Epstein RM, Duberstein P, Willeford L, Kravitz RL Barriers in diagnosing and treating men with depression: a focus group report. American journal of men's health. 2010;4(2):167-75.

42. Smith JA, Braunack-Mayer A, Wittert G, Warin M. "It's sort of like being a detective": Understanding how Australian men self-monitor their health prior to seeking help. BMC Health Serv Res. 2008;8(56):10.

43. Steinfeldt JA, Steinfeldt MC. Gender role conflict, athletic identity, and help-seeking among high school football players. Journal of Applied Sport Psychology. 2010;22(3):262-73.

44. Vogel DL, Heimerdinger-Edwards SR, Hammer JH, Hubbard A. "Boys don't cry": Examination of the links between endorsement of masculine norms, self-stigma, and help-seeking attitudes for men from diverse backgrounds. J Couns Psychol. 2011;58(3):368.

45. Currier D, Pirkis J, Carlin J, Degenhardt L, Dharmage SC, Giles-Corti B, Gordon I, Gurrin LC, Hocking J, Kavanagh AM, et al. The Australian longitudinal study on male health - methods. BMC Public Health. In press

46. Australian Bureau of Statistics. Australian Statistical Geography Standard (ASGS): volume 5-remoteness structure. Canberra: Australian Bureau of Statistics; 2011.

47. Australian Bureau of Statistics. In: ABS, editor. ABS Household Expenditure Survey and Survey of Income and Housing Costs, vol. 2016. Canberra: Australian Bureau of Statistics; 2003.

48. Barbor TF, Higgins-Biddle JC, Saunders JB, Monteiro MG. AUDIT - the alcoho use disorders identification test: guidelines for use in primary care. 2nd ed. Geneva: World Health Organisation; 2001.

49. Ware JE, Kosinski M, Turner-Bowker DM, Gandek B. How to Score Version 2 of the SF-12 Health Survey. Lincoln: QualityMetric Incorporated; 2002.

50. Dixon J, Welch N. Researching the rural-metropolitan health differential using the 'social determinants of health'. Aust J Rural Health. 2000;8(5):254-60.

51. Humphreys J. Rural health status: what do statistics show that we don't already know? Aust J Rural Health. 1999;7(1):60-3.

52. Wilkinson D, Blue I. The new rural health: Oxford University Press; 2002

53. Humphreys JS, Jones MP, Jones JA, Mara PR. Workforce retention in rural and remote Australia: determining the factors that influence length of practice. Med J Aust. 2002;176(10):472-6.

54. Bourke L, Sheridan C, Russell U, Jones G, DeWitt D, Liaw ST. Developing a conceptual understanding of rural health practice. Aust J Rural Health 2004;12(5):181-6.

55. Adler NE, Boyce T, Chesney MA, Cohen S, Folkman S, Kahn RL, Syme SL. Socioeconomic status and health: the challenge of the gradient. Am Psychol. 1994;49(1):15.

56. Hiscock R, Bauld L, Amos A, Fidler JA, Munafo M. Socioeconomic status and smoking: a review. Ann N Y Acad Sci. 2012;1248(1):107-23.

57. Harris $M$. The role of primary health care in preventing the onset of chronic disease, with a particular focus on the lifestyle risk factors of obesity, tobacco and alcohol. Canberra: National Preventative Health Taskforce; 2008. p. 1-21.

58. Dowell A, Hilton S, Bland J, Harris T, Jones D, Katbamna S. Prevention in practice: results of a 2-year follow-up of routine health promotion interventions in general practice. Fam Pract. 1996;13(4):357-62. 
59. Boulware LE, Marinopoulos S, Phillips KA, Hwang CW, Maynor K, Merenstein D, Wilson RF, Barnes GJ, Bass EB, Powe NR. Systematic review: the value of the periodic health evaluation. Ann Intern Med. 2007;146(4):289-300.

60. Harris $\mathrm{M}$. The role of primary health care in preventing the onset of chronic disease, with a particular focus on the lifestyle risk factors of obesity, tobacco and alcohol. In: Prevention Health Task Force. 2008.

61. Department of Health. MBS Health Assessments Items 701, 703, 705, 707, 715 and 10986. Canberra: Department of Health; 2015.

62. White A, McKee M, Richardson N, de Visser R, Madsen SA, de Sousa BC, Hogston R, Zatoński W, Makara P. Europe's men need their own health strategy. BMJ. 2011;343:d7397; doi:10.1136/bmj.d7397.

Submit your next manuscript to BioMed Central and we will help you at every step:

- We accept pre-submission inquiries

- Our selector tool helps you to find the most relevant journal

- We provide round the clock customer support

- Convenient online submission

- Thorough peer review

- Inclusion in PubMed and all major indexing services

- Maximum visibility for your research

Submit your manuscript at www.biomedcentral.com/submit
Biomed Central 